\title{
The Fold Style Variations of Baikher Anticline - Northern Iraq
}

\author{
Nabeel K. Al-Azzawi Safwan T. Al-Hubiti \\ Department of Geology \\ College of Science \\ Mosul University
}

(Received 25/5/2008, Accepted 8/10/2008)

\begin{abstract}
The changes in fold style of Baikher Anticline were obtained by determining the fold shape, the values of interlimb angle and the degree of cylindricity in four crosssectional traverses. The fold shape was calculated mathematically using the Fourier analysis method whereas the Ramsay and Huber classification method was applied for deciphering the cylindricity of the fold and the Pi-diagrams for determining the values of interlimb angle in each traverse.

The axial changes of the fold style revealed that the area that is occupied by Baikher Anticline was divided structurally into four segments according to their trend and vergence besides their comparison laterally with the related faults.

Data analysis revealed that Baikher Anticline is double plunging, asymmetrical, open to gentle and cylindrical in the four segments, whereas the fold vergence and shape differ from a segment to another. Baikher Anticline is verged southwestwards in the first and third segments, northeastwards in the second segment and northwards in the forth one. The analyses revealed that the fold shape ranges from chevron to box shape from traverse to another.

The anticline related faults fall into two categories. The first is a set of strike-slip type which influenced the fold trend whereas the second is listric faults that affected the fold vergence.

Vertical investigations of fold style were also carried out in the second and third traverses. The second traverse proved the Middle Eocene reactivation of the foreland listric fault, whereas unexpected vergences showed in the third one.
\end{abstract}




\title{
تغيرات طراز طية بيخير المحبة - شمال العراق
}

\author{
نبيل قادر العزاوي

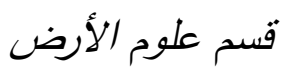 \\ كلبة العلوم الارض

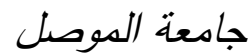

الملخص

لقد وجدت تغيرات طراز طية بيخير المحدبة من حساب شكل الطية، قيم الزاوية الداخلية للطية ودرجة

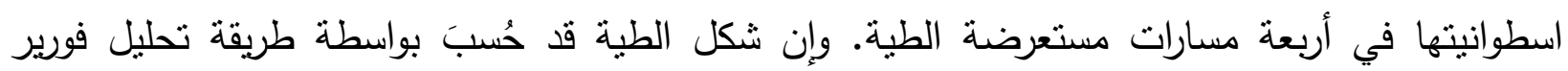

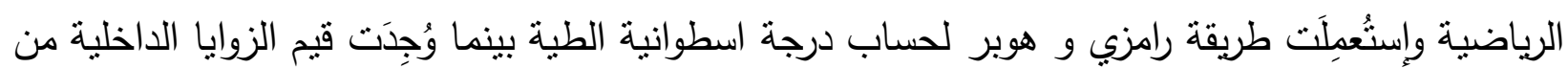
رسم أنثكال باي للطية.

تُظهِر التغيرات المحورية لطراز الطية أن المنطقة التي تحنويها طية بيخير تُشَم تركيبياً إلى أربعة

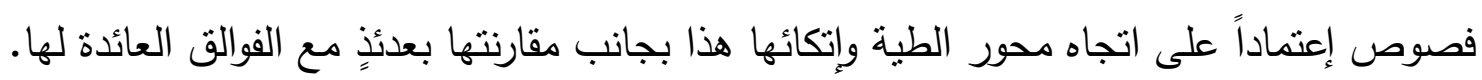

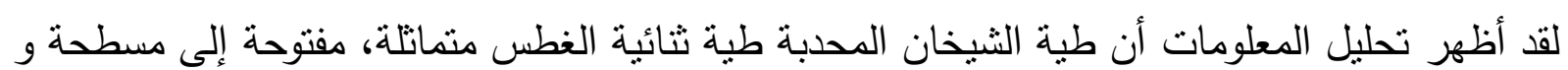
اسطوانية في الفصوص الأربعة. بينما يختلف اتكاء الطية وشكلها من فص إلى آخر حيث تتكئ طية بيخير

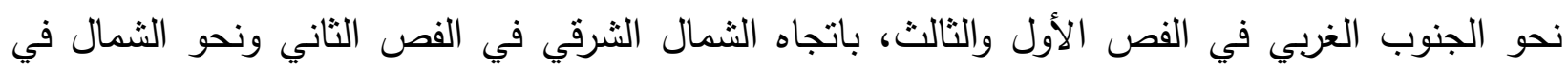
الفص الرابع. وأظهر التحليل أن شكل الطية يتغير بين المسارات من شكل الطية الثفرونية إلى شكل الطية

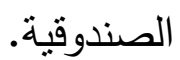

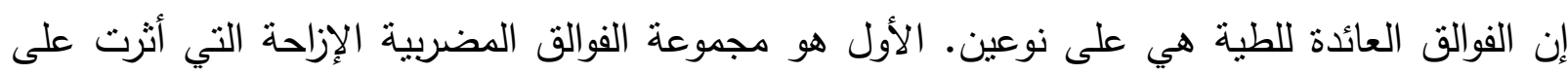
أنجاه الطية أما النوع الثاني فهو مجموعة الفوالق اللستيرية التي أثرت على إنى إنجاه إتكاء الطية.

\section{INTRODUCTION}

The Foreland Belt of Iraq which is a part of the Alpine orogeny was divided by Bolten (1958) into three parts. They are the Thrust Zone which occupied the northeastern part, the Folded Zone that is sandwiched between the first and third zones and the Unfolded Zone which is located southwesterly. The Folded Zone was also divided into two parts. They are the High Mountain Belt which is located northeastwards and the Foothill Belt that is situated southwesterly. The folds of the Foreland Belt of Iraq yield two main directions of trends. The first trend is parallel to the direction of the Zagros Range (northwest-southeast), whereas the other coincides with the direction of the Taurus Range (east-west).

Baikher Anticline is situated within the northern part of Iraq, about $60 \mathrm{Km}$ north of Mosul city. It occupies a very large area from Zawita to Deraboon villages and located 


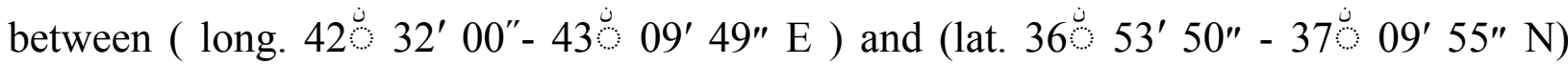
(Fig.1).

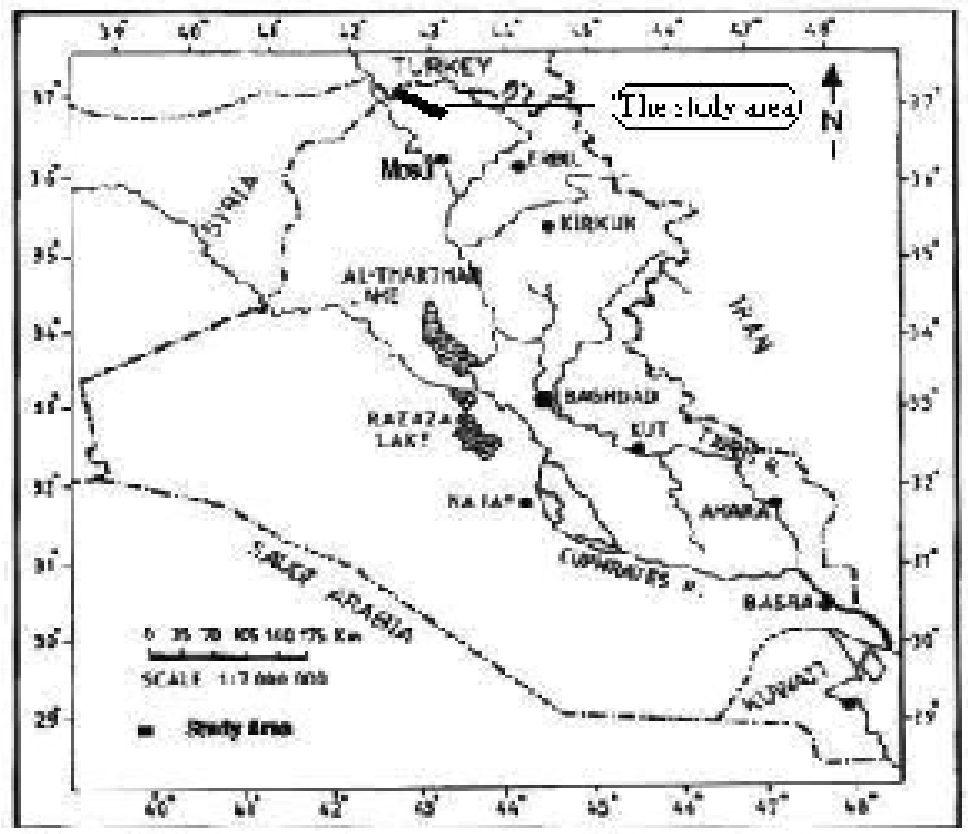

Fig. 1: Location map of the study area.

Stratigraphically, the area of this anticline composed of several geologic formations ranging in time span from Cretaceous to Miocene periods. It embraces the following exposed formations in ascending order. The Bekhme Fn. (Late Cretaceous) has basal conglomerates comprising globigerinal and foraminiferal limestones, reefal-detrital limestones and bituminous secondary dolomites. The Shiranish Fn. ( Late Cretaceous) consist of upper division of blue marls, overlying lower division of thin bedded marly limestone. The beds weather in typical pale blue color but are dark blue on fresh fracture. The Kolosh Fn. (Paleocene - Early Eocene) is composed of shale, fine sandstone and fragments of various grains of green-rock, chert and radiolarite. It also comprises lenses of Khurmala Fn. ion its upper part. The Gercus Fn. (Middle Eocene) is composed of red and purple shales, mudstones, sandy and gritty marls. The formation comprises lenses of Avanah Limestone Fn. and in order to determine the thickness of Gercus Fn., these lenses were considered within it. The Pila Spi Fn. (Middle to Late Eocene) consists of bedded limestones, hard, chalky appearance, porous or vitreous, bituminous or white and poorly fossiliferous. The Fat'ha Fn. (Middle Miocene) consists of gypsum and salt intercalated with limestones and marls. Finally the Injana Fn. (Late Miocene) is composed of subcontinental and continental purple, red, brown and grey marls, silts, siltstones, sandstones and grits. The brief description of the lithology of each formation was taken from Van Bellen et al., (1959).

Previously, many regional studies mildly mentioned the structure of Baikher Anticline (Taufiq and Domas, 1977; Al-Shaibani, 1973; Al-Duski, 2004). However, there are two intensive studies that described the structure of this anticline (Ameen, 1979; Al-Alawi, 1980). The present work can be considered a trend of study that was not previously taken into consideration. It focuses on the variations of the tectonic style of folding both spatially and vertically. 
All the previous authors had described Baikher structure as very long, asymmetrical and double plunging anticline. Ameen (1979) studied this anticline through two large and regional traverses and stated that the anticline has a trend parallel to Taurus Range between Zawita village and Dohuk city, changed to the trend of Zagros Range between Dohuk and Zakho cities and returned to Taurus trend from Zakho city to Deraboon village. The same author also mentioned that Baikher Anticline has a vergency towards the southwest in most of the anticline body and having a steep or an overturned northern limb in the area between Zakho and Deraboon. Al-Alawi (1980) described the changes of the fold axis direction in the same manner that was mentioned in Ameen (1979). Al-Alawi (1980) also suggested that Baikher Anticline consists of two parts. The first part located between Zawita village and Germawa valley and was called Spi Rais Fold, whereas the second one occupied the area between Germawa valley and Sheizi village and was named Gara Baran Fold. This author also complemented his work by the structural analyses of the major and minor folds and joints.

\section{The general fold description:}

The general description of Baikher Anticline is taken from the field observations and the satellite imagery. The anticline is generally asymmetrical double plunging fold, located within the High Mountain Belt of the Iraqi Foreland and extends about $72 \mathrm{Km}$ from Zawita/Besari area (the southeastern plunge) to Deraboon village near the IraqiSyrian-Turkish boarder (the northwest plunge).

The southeastern plunge of Baikher Anticline has a triangular shape and the base of this triangle occupies the area from Zawita village to Besari valley. The anticline starts from this area and extends west- northwesterly to Kuwasha village (Fig. 2) parallel to the direction of the Zagros Range. The anticline in this area is very wide with exposures of the Cretaceous and Tertiary rocks and contains the two parts (Spi Rais and Gara Baran folds). Germawa valley is considered as a saddle which separates Spi Rais from Gara Baran. The anticline more or less maintains its direction from Kuwasha village to Gali Zakho. A notable swing of the anticline axis appears near Kuwasha village called Kuwasha swing. The anticline width in the area (between Kuwasha and Gali Zakho) is narrow relative to the previous part and characterized by the exposures of the Tertiary rocks only. This width tends to be further narrower between Gali Zakho and Deraboon village (the western plunge). In this area, the axis of the anticline follows the trend of Taurus Range (east-west) and there is no rock older than the Pila Spi Formation. Accordingly, Baikher Anticline may be divided into four parts according to the variation of its axial trend as mentioned above. The other anticline properties were checked with respect to these divisions latterly.

Baikher Anticline is asymmetrical. However, its vergence varies from a place to another. In some places, the fold verges towards the southwest. Other places show an opposite vergence (northward or northeastward). The field work and satellite imagery observations were used here in a preliminary step to divide the anticline into four segments according to the axial direction changes and the vergence differences, whereas the geometric analyses of field data clarified the characters of these segments.

The differences in the axial trend of this anticline revealed that it was influenced by a set of sinistral and dextral strike-slip faults (Fig. 2). While the opposing vergences reflect the existence of two opposite dipping listric faults that molded the vergence of the 
The Fold Style Variations of Baikher Anticline.....

anticline (compare with Al-Azzawi ,2003). These sets of faults will be discussed in the course of this work. 
Nabeel K. Al-Azzawi and Safwan T. Al-Hubiti

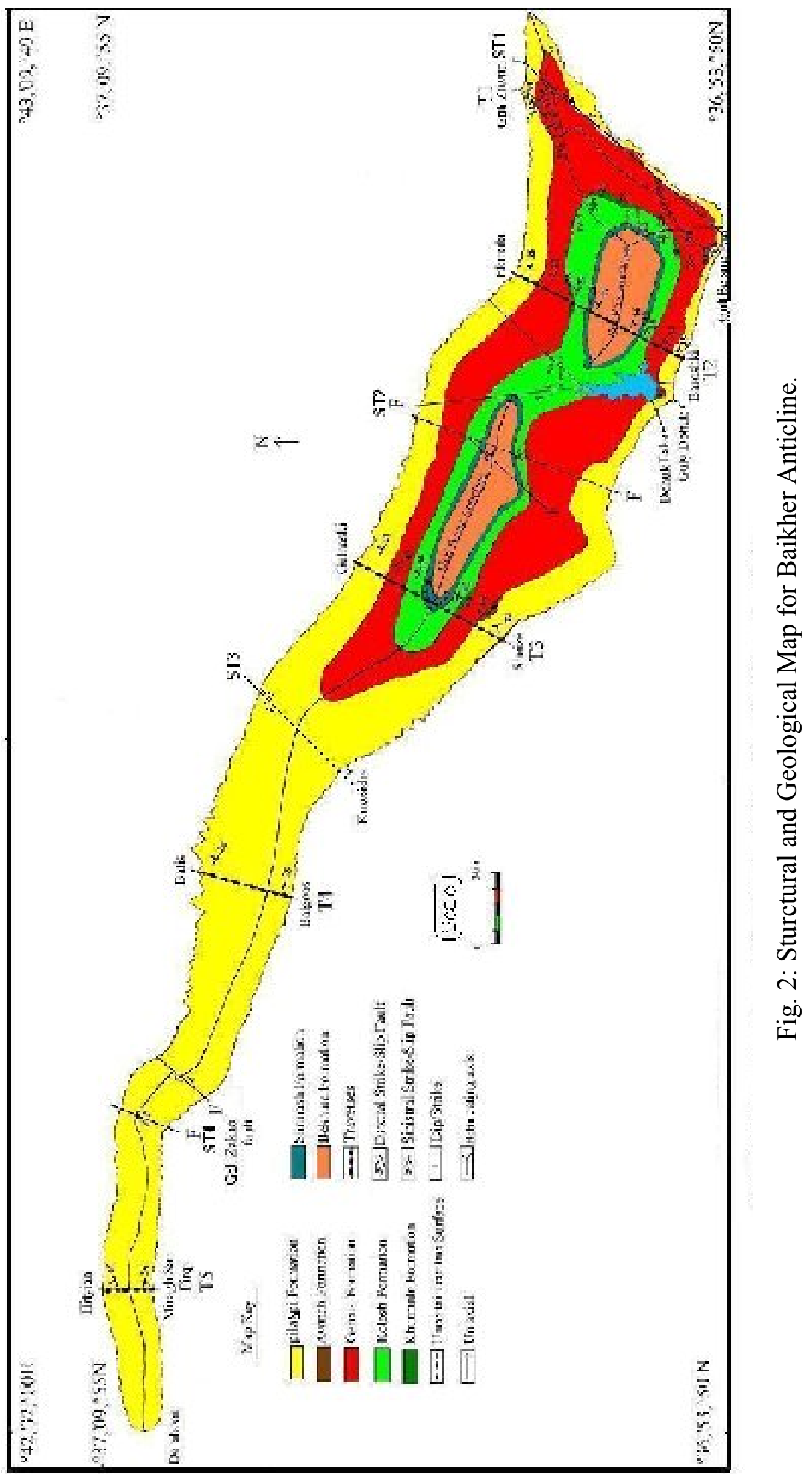




\section{The tectonic style of the fold:}

The term Tectonic style have been introduced by Lugeon in (Turner and Wiess, 1963) and used for the description of all tectonic structures including folds (Hobbs et al., 1967). While the term Fold style was used specially to describe the type of folding for any anticline or syncline (Van der Plujim and Marshak, 1997). Fold style or tectonic style of fold depends on the fold shape in cross-section, the presence of the axial plane foliations and lineations and if the fold is cylindrical or not (Hobbs et al., 1976).Van der Plujim and Marshak (1997) suggested that the fold style is controlled by several factors such as type of folding (Parallel or similar), value of the interlimb angle, whether the fold is cylindrical or not and presence or absence of foliations or lineations.

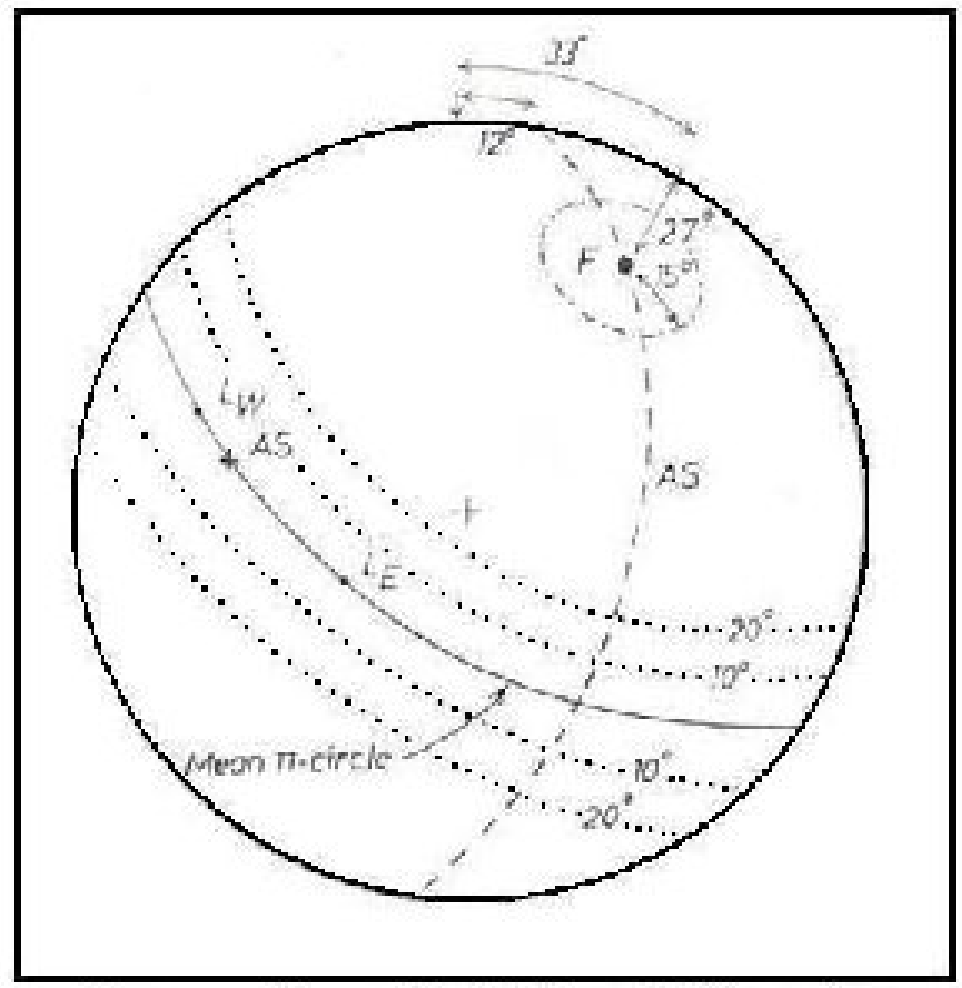

Fig. 3: The cylindricity of folds, after Ramasay and Huber (1987).

For the sake of applying the tectonic style of fold in the study area, it seemed that some of these factors are not compatible with the nature of this area. First of all the foliations are not present in the structure of the area. Secondly, the constructions of the fold profiles depended on the basis of Busk method which assumed that the fold should be of the parallel type. And the limestone beds of the Pila Spi Formation which were used, in this work to represent the fold shape, are competent and maintained their thicknesses during folding. Accordingly, the fold of the limestone bed must be considered as parallel type. So this factor was not considered in the scope of the present study.

Consequently, there are three important factors which were taken into consideration in the study of the fold tectonic style. They are:

1- The fold shape in cross-section: In this study, Fourier analysis method was used to determine the shape of the fold in cross-section. This method was fully described in Singh and Gairola (1992) and Al-Azzawi (2003). 
2- The fold cylindricity: For determining the degree of cylindricity of Baikher Anticline in cross-sections, a classification method that cited by Ramsay and Huber (1987) was used (Fig.3). The method groups out the folds into four categories, namely perfect cylindrical, cylindrical, sub- cylindrical and non- cylindrical fold.

3- The interlimb angle: values of the interlimb angles which were determined from the constructed Pi-diagrams were used for comparing the investigated traverses.

\section{Analysis of field data:}

The structure of Baikher anticline was analyzed in details through five traverses. These traverses were cross cut and uniformly distributed on the axis of the anticline (Fig.2). It is to be noted that the attitude of any plane was taken as strike direction / dip amount and the strike direction was taken clockwise from the dip direction. And the attitude of any line was taken as dip direction/ dip amount. A full geometric description of Baikher Anticline in these traverses is shown below:

\section{The first traverse T1:}

This traverse extends between Gali Besari in the south and northward to Gali Zawita. The study of this traverse concentrated on the nature of the fold axis at the wide southeastern plunge of the anticline. So that data of bedding planes were taken along this traverse with spacing equal to $200 \mathrm{~m}$. Subsequently, by plotting the bedding symbols on the map, it was found that the axis of this anticline has bifurcating shape at this wide plunge area. It was bifurcated into two branches at the southeastern contact of Bekhme Formation (Fig. 2). One of them that plunges near Gali Zawita represented by the plunge of the Gercus, Pila Spi, Fatha and Injana formations. Whereas the other plunges at Emenki village (near Gali Besari) and this plunge was represented by the Gercus and Pila Spi formations (Fig. 2). This is because the Fatha and Injana formations were eroded or sometime covered by alluvial deposits.

\section{The second traverse T2:}

Data of this traverse was collected along line crossing the Spi Raise fold through Baroshki and Ekmala villages (Fig. 2). Bekhme, Shiranish, Kolosh, Gercus, Pila Spi and Fatha formations were exposed within this traverse. The construction of Pi-diagram for the anticline in this traverse revealed that the mean attitudes of the southwestern and the northeastern limbs are equal to $285 / 45$ and $110 / 21$ respectively. The interlimb angle is equal to 112 degree, the attitude of the fold axis is $102 / 03$ and that of the axial plane is 102/81 (Fig. 4). The geometric analysis of the anticline in this traverse revealed that it is asymmetrical anticline verging southwestwards. The geologic cross-section showed that the amplitude and the half wavelength are equal to $2000 \mathrm{~m}$ and $8600 \mathrm{~m}$ respectively (Fig. 5). The anticline, in this traverse, was classified as cylindrical fold according to Ramsay and Huber (1987). This is because $90 \%$ of its S-poles were plotted within $\pm 10^{\circ}$ around the pi-circle. It is also classified as open and horizontal upright fold according to Fleuty (1964) and also horizontal upright fold according to Rickard (1971). 


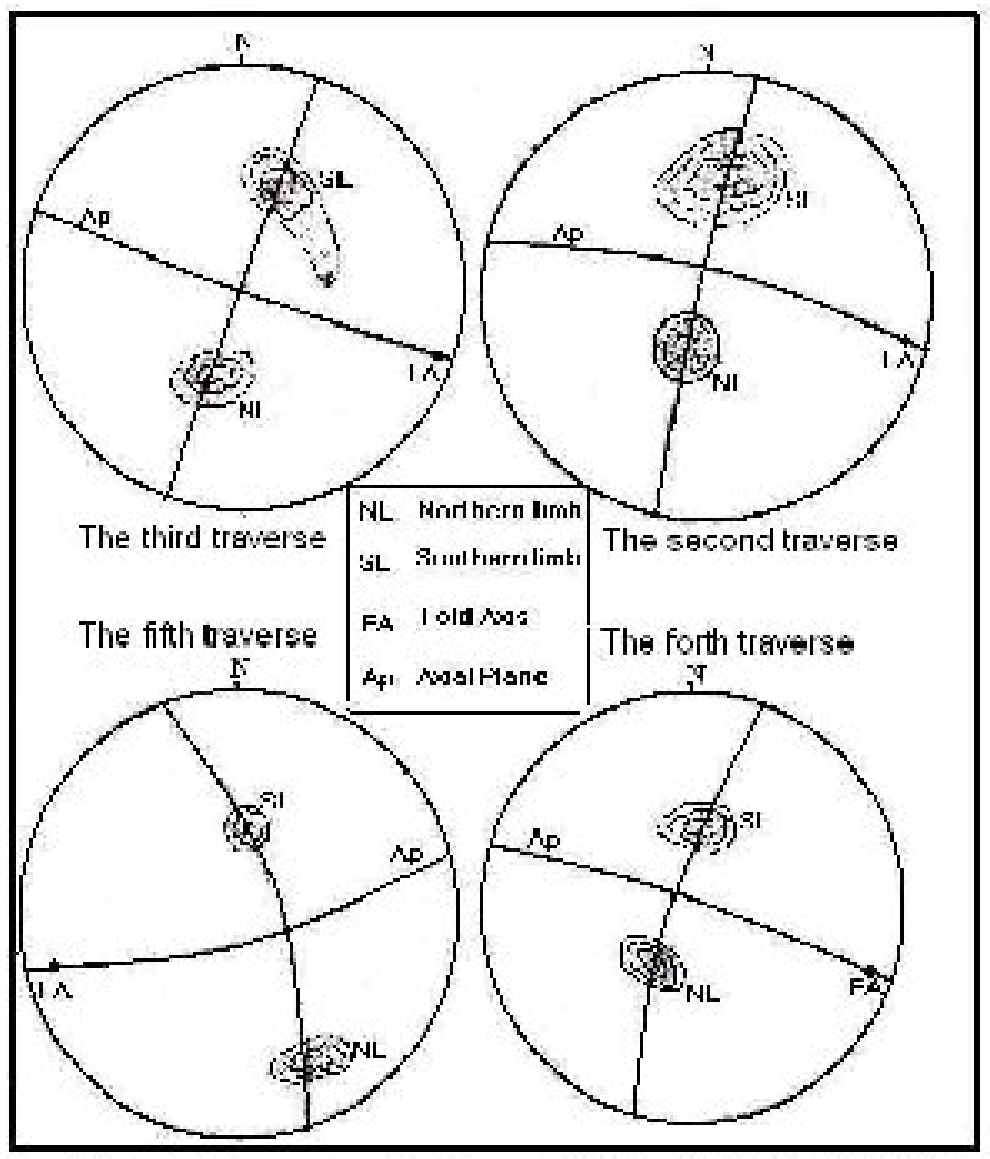

Fig. 4: The Pi-diagrams of Baikher Anticline in the four traverses.

\section{The third traverse T3:}

This traverse was connecting Sheizi and Gulnaski villages crossing Baikher Anticline at Gara Baran segment (Fig. 2). The same formations that exposed in the previous traverse were exposed here, except Bekhme Formation which was exposed outside the scope of this traverse. The analysis of field data by constructing pi-diagram showed that the mean attitudes of the southwestern and northeastern limbs are 290/35 and $109 / 41$ respectively. The interlimb angle is equal to $111^{\circ}$, the attitude of the fold axis is $108 / 02$ and the attitude of the axial plane is 110/88 (Fig. 4). This analysis revealed that the anticline is asymmetrical and verging towards the northeast. Its amplitude and half wavelength which were measured from the geologic cross-section are equal to $2100 \mathrm{~m}$ and $7500 \mathrm{~m}$ respectively (Fig. 5). The anticline in this traverse was also classified as cylindrical fold according to Ramsay and Huber (1987). And it is classified as open and horizontal upright fold according to Fleuty (1964) and also horizontal upright fold according to Rickard (1971).

\section{The forth Traverse T4:}

The areas of this traverse and the fifth traverse are not studied by the previous works of Al-Alawi (1980) and Ameen (1979). The forth traverse crossed the anticline and connected Balgoos and Batis villages (Fig. 2). Data was collected from Pila Spi, Fatha and Injana formations and there is no exposure of rocks older the Pila Spi Formation. Pi-diagram of the anticline in this traverse showed that the mean attitudes of the southwestern and northeastern limbs are 281/35 and 120/24 respectively. The attitude 
of the fold axis, the interlimb angle and the axial plane attitude are equal to $112 / 06,122^{\circ}$ and 122/86 respectively (Fig. 4). Therefore, the anticline in this traverse is asymmetrical with southwestwards vergence, it is classified as cylindrical fold according to Ramsay and Huber (1987), gentle and horizontal upright fold according to Fleuty (1964) and also classified as horizontal upright fold according to Rickard (1971). The amplitude and the half wavelength in this area are equal to $1220 \mathrm{~m}$ and $4500 \mathrm{~m}$ respectively.

\section{The fifth traverse T5:}

This traverse is located in the western part of Baikher Anticline. It extends between Miragh Sar Firq and Hityian villages and far from the western plunge about $5.9 \mathrm{Km}$ (Fig. 2). Baikher Anticline in this area was completely changed its direction; it became parallel to the trend of the Taurus Range. Stratigraphically, the Pila Spi Formation is the older formation that is exposed in this area. The geometrical analysis by constructing Pidiagram revealed that the mean attitudes of the southern and the northern limbs are $280 / 32$ and 064/65 respectively. The attitude of the fold axis, the interlimb angle and the axial plane are $258 / 19,86^{\circ}$ and $270 / 72$ respectively (Fig. 4). The amplitude and half wavelength of Baikher Anticline in this traverse are equal to $860 \mathrm{~m}$ and $2600 \mathrm{~m}$ respectively. The anticline is also classified as cylindrical fold according to Ramsay and Huber (1987), open and horizontal upright fold according to Fleuty (1964) and Horizontal fold according to Rickard (1971).

\section{Determination of fold shape:}

The study of the tectonic style of Baikher Anticline needs fold shape determinations in each traverse. These determinations were carried out using Fourier analysis method (Harmonic method). It is a series of trigonometric functions used to express the shape of any curve and here to express the profile of the fold. This method was fully described by Ramsay and Huber (1987) and Singh and Gairola (1992)). Al-Azzawi (2003) gave a practical description of this method (Fig. 6).

The Stabler axes $y_{1}, y_{2}$ and $y_{3}$ are measured from the fold profile (the quarter wavelength) which was constructed by Busk method. The Fourier coefficients $b_{1}, b_{3}$ and $b_{5}$ are calculated using the Fourier following equations:

$$
\begin{aligned}
& \mathrm{Y}_{1}=b_{1} \text { SIN X }_{1}+b_{3} \text { SIN } 3 X_{1}+b_{5} \text { SIN } 5 X_{1} \\
& Y_{2}=b_{1} \text { SIN X } x_{2}+b_{3} \text { SIN } 3 X_{2}+b_{5} \text { SIN } 5 X_{2} \\
& Y_{3}=b_{1} \text { SIN X } X_{3}+b_{3} \text { SIN } 3 X_{3}+b_{5} \text { SIN } 5 X_{3}
\end{aligned}
$$

These equations were simplified by Stabler (1968) to the following formulas:

$$
\begin{aligned}
& \mathrm{b}_{1}=1 / 3\left(\mathrm{y}_{3}+\mathrm{y}_{1}\right)+\left[\mathrm{y}_{2} /(2 \sin 60)\right] \\
& \mathrm{b}_{3}=1 / 3\left(2 \mathrm{y}_{1}-\mathrm{y}_{3}\right) \quad[1 /(2 \sin 60)] \\
& \mathrm{b}_{5}=1 / 3\left(\left(\mathrm{y}_{3}+\mathrm{y}_{1}\right)-\mathrm{y}_{2} /(2 \sin 60)\right)
\end{aligned}
$$

Therefore, these coefficients can be plotted in Hudleston diagram (Hudleston, 1973a) to determine the shape of the studied profile (Fig. 7). The variations of fold shape in the studied traverses are shown in table (1). And because this method was dealt with quarter wavelength, the shape of each limb was determined. 
The Fold Style Variations of Baikher Anticline.....

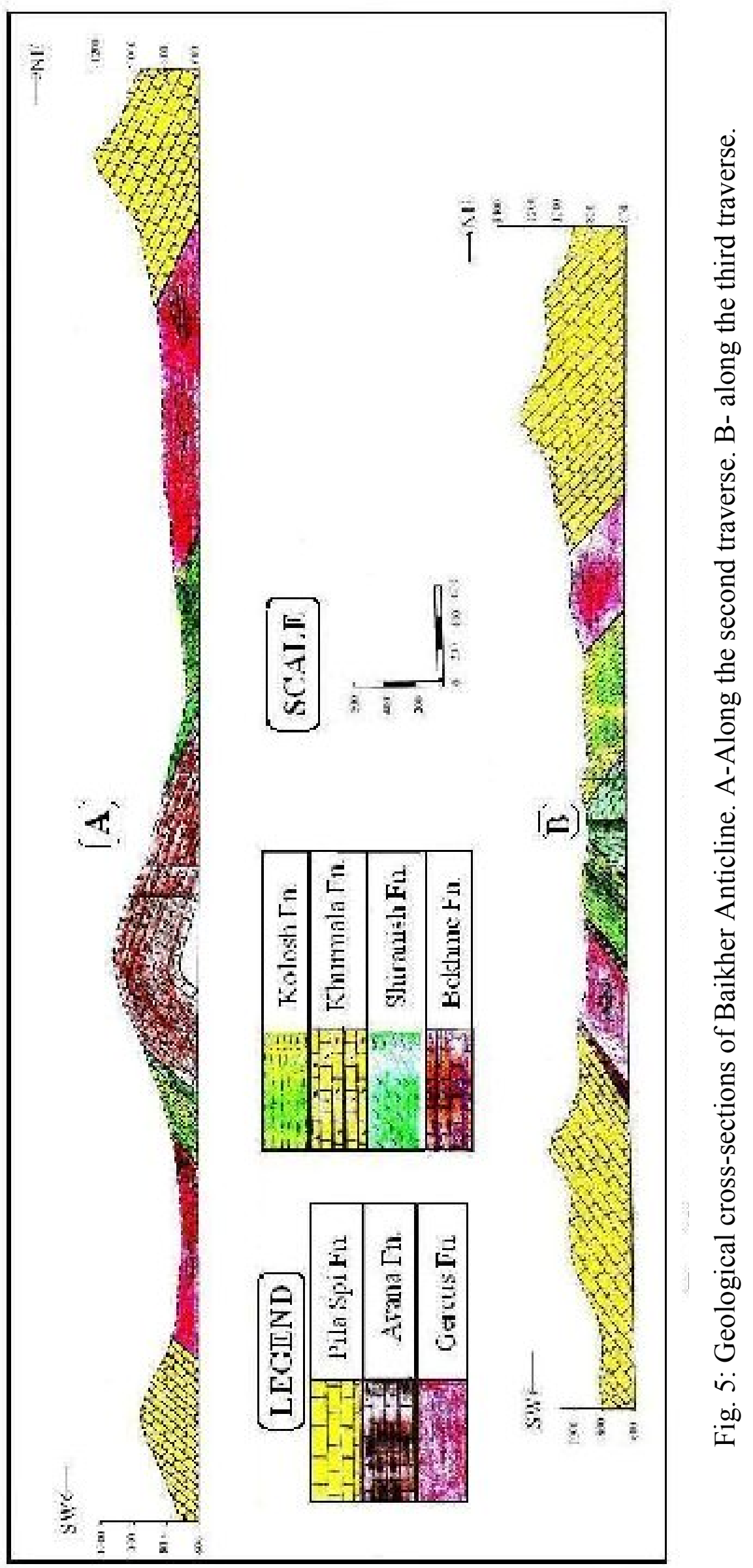




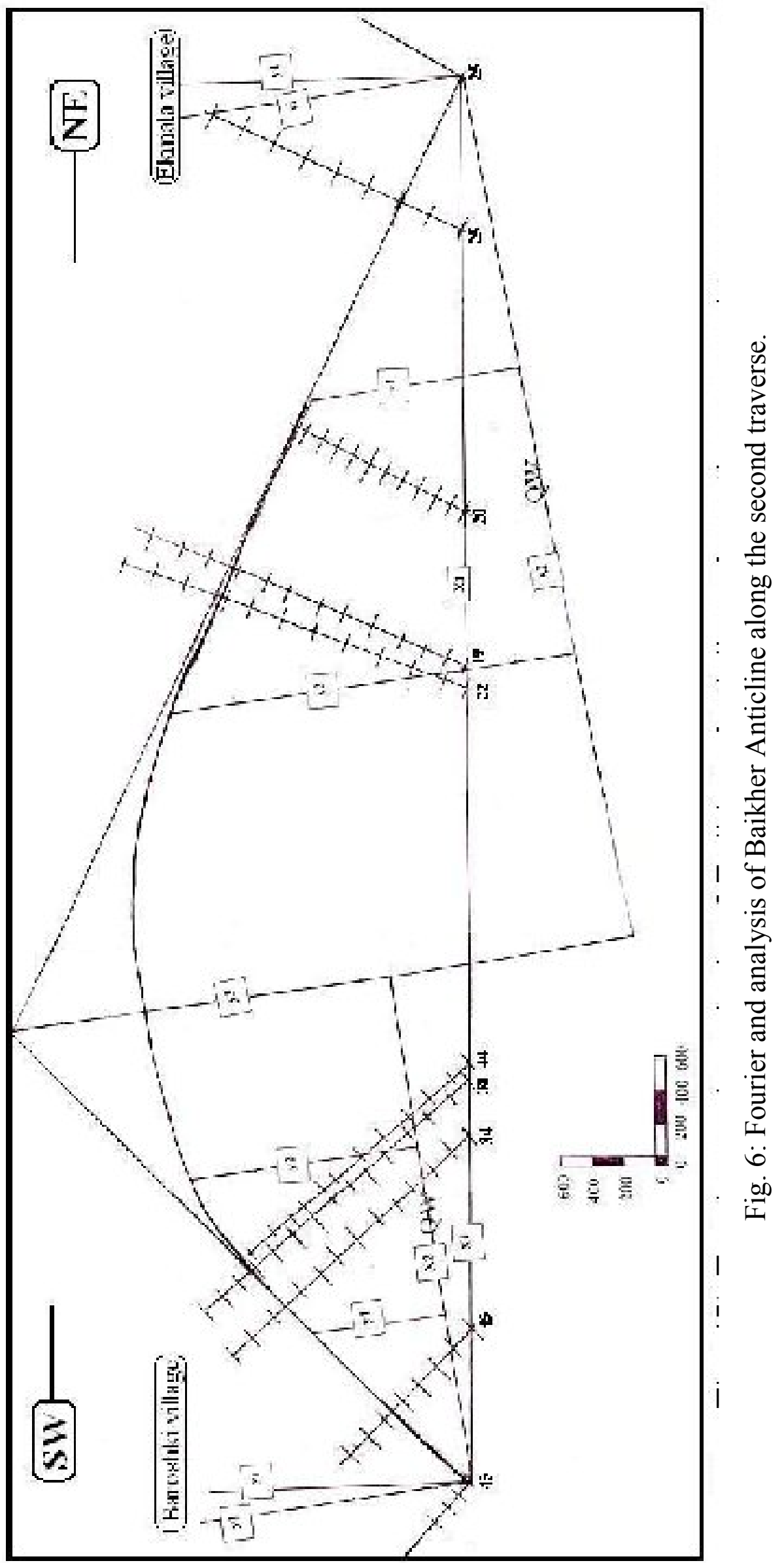




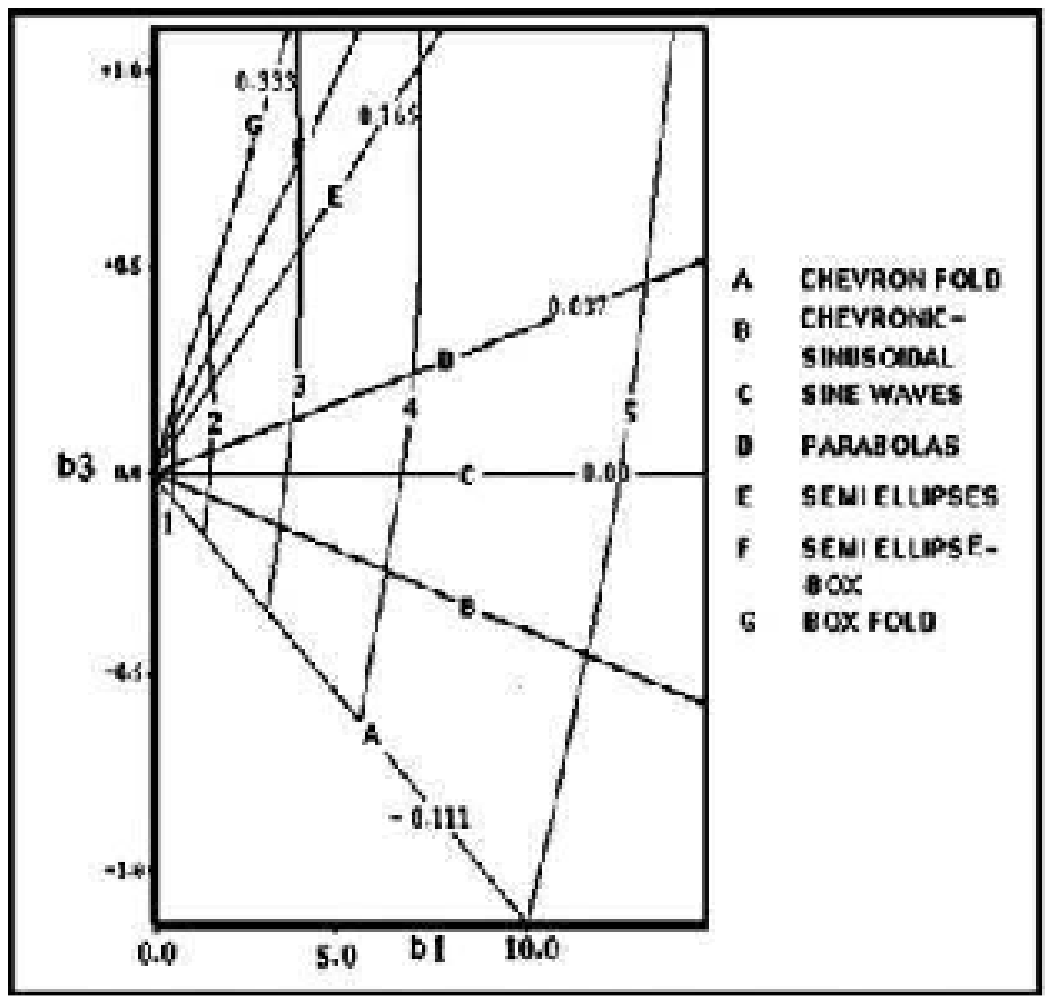

Fig. 7: Hudleston classification, after (hudleston, 1973a).

\section{The axial changes of fold style:}

As it was mentioned previously, the tectonic style of Baikher Anticline was essentially controlled by three factors. They are the fold cylindricity, the interlimb angle and the fold shape in profile. Therefore, the variations of tectonic style along Baikher Anticline can be discussed in the scope of those three factors:

1- The fold cylindricity: This factor was determined in four of the five traverses (except the first traverse). All of them showed that Baikher Anticline is cylindrical fold. Therefore, there is no difference in the cylindricity of the anticline in these traverses.

2- The interlimb angle: The constructions of the pi-diagrams showed that . The interlimb angle values are equal to $112^{\circ}, 93^{\circ}, 122^{\circ}$ and $86^{\circ}$ in the second, third, forth and fifth traverses. The values of the second, third and forth traverses are caused the anticline to classify as open fold, whereas it classifies as gentle fold in the fifth traverse according to Fleuty (1964).

3- The fold shapes in the profiles: The fold shapes were determined in the traverses using Fourier analysis which was applied on quarter wavelength. It means that each limb has its own shape. The present authors tried to compare the shape of fold in each limb with the fold vergence and to correlate these with the movement of the relating listric faults. It was found that the fold shape became more developed in the steeper limbs (table 1). The fold shape appeared Parabolic and chevronic in the southwestern and northeastern limbs of the anticline in the second traverse respectively. Whereas it has an opposite attitude in the third traverse. In the forth traverse, it appeared as chevron and under-chevron fold in the southwestern and northeastern limbs. Analysis of the fifth traverse revealed large difference between the southern and northern limb. The former has chevron shape whereas the box shape characterized the later one. 
Accordingly, four distinct segments were recognized to describe the lateral variations of the tectonic style of Baikher Anticline. These segments are characterized by variations in some structural features in addition to the shape and the interlimb angle. These features are the fold vergence, fold axis trend and the interaction of listric faults through out the folding.

Table 1: The shapes of Baikher Anticline in the studied traverses.

(FR is Fourier Ratio).

\begin{tabular}{|c|c|c|}
\hline The traverse & Shape of the $\mathbf{N}$ or NE limb & Shape of the $\mathbf{S}$ or $\mathbf{S W}$ limb \\
\hline T2 & Chevron fold $/ \mathrm{FR}=-0.043$ & Parabolic fold $/ \mathrm{FR}=0.018$ \\
\hline $\mathrm{T} 3$ & Parabolic fold $/ \mathrm{FR}=0.019$ & Chevron fold $/ \mathrm{FR}=-0.106$ \\
\hline $\mathrm{T} 4$ & Under-Chevron $\mathrm{FR}=-0.125$ & Chevron fold $/ \mathrm{FR}=-0.086$ \\
\hline T5 & Box fold $/ \mathrm{FR}=0.73$ & Chevron fold $/ \mathrm{FR}=-0.052$ \\
\hline
\end{tabular}

\section{The first segment:}

This area extended from Zawita/Besari to Germawa valley through Dohuk city. It is occupied by the Spi Raise fold (T2). Baikher Anticline in this segment is characterized by west northwest- east southeast trend of the fold axis, asymmetrical with southwestwards vergence, open fold, cylindrical and its southwestern limb more developed in shape (Parabolic) than the northeastern one (Chevronic). It means that the steeper limb is more developed than the gentle one (Fig. 2 and 4).

\section{The second segment:}

This segment is occupied by the Gara Baran fold (T3). It extends from Germawa valley to Kawasha village. The anticline in this area is asymmetrical, open, cylindrical fold and characterized by northeastwards vergence (Fig. 2 and 4). The northeastern limb of the anticline in this area has Parabolic shape while the other limb has chevron shape. This structural phenomenon has an important tectonic implication. It was formed due to the influence of listric fault which will be discussed later. The anticline in this area changed its direction to northwest-southeast.

\section{The third segment:}

The area of this segment extends from Kawasha village to Gali Zakho (T4). The anticline in this area is asymmetrical, gentle, cylindrical fold and verging towards the southwest (Fig. 2 and 4)). The northeastern limb in this segment has under-chevron shape and the other limb has chevron shape. The fold axis direction remained northwestsoutheast with little difference from the previous segment. Criteria of this segment imply that this area was not affected by listric faults. These are the anticline in this segment has gentle interlimb angle and it verged towards southwest without considerable difference in the dips between the northeast and the southwest limbs.

\section{The forth segment:}

This area is located between Gali Zakho and the western plunge of Baikher Anticline (T5). The anticline in this area is characterized by its east-west trend parallel to the general trend of Taurus Range, asymmetrical with northwards vergence, open, 
cylindrical and has a distinct box shape in the northern limb while the southern one has a chevron shape (Fig. 2 and 4).

The variations of fold properties among the four segments indicate lateral variations in the tectonic style of Baikher Anticline(Fig. 2 and 4). There are two most distinct structural features that specify these variations along this Anticline. Firstly, the changes in the axial direction from west northwest (in the first segment), to northwest (the second and third segments) and to west (the forth segment). The changes of the axial direction were influenced by some strike-slip faults (Fig. 8). Secondly, the oppositions of fold vergence along Baikher Anticline. The fold is verging towards southwest in the first segment, to the northeast in the second, to the southwest in the third segment and northwards vergency in the forth one. These vergence variations were related in origin to the listric faults mechanisms.

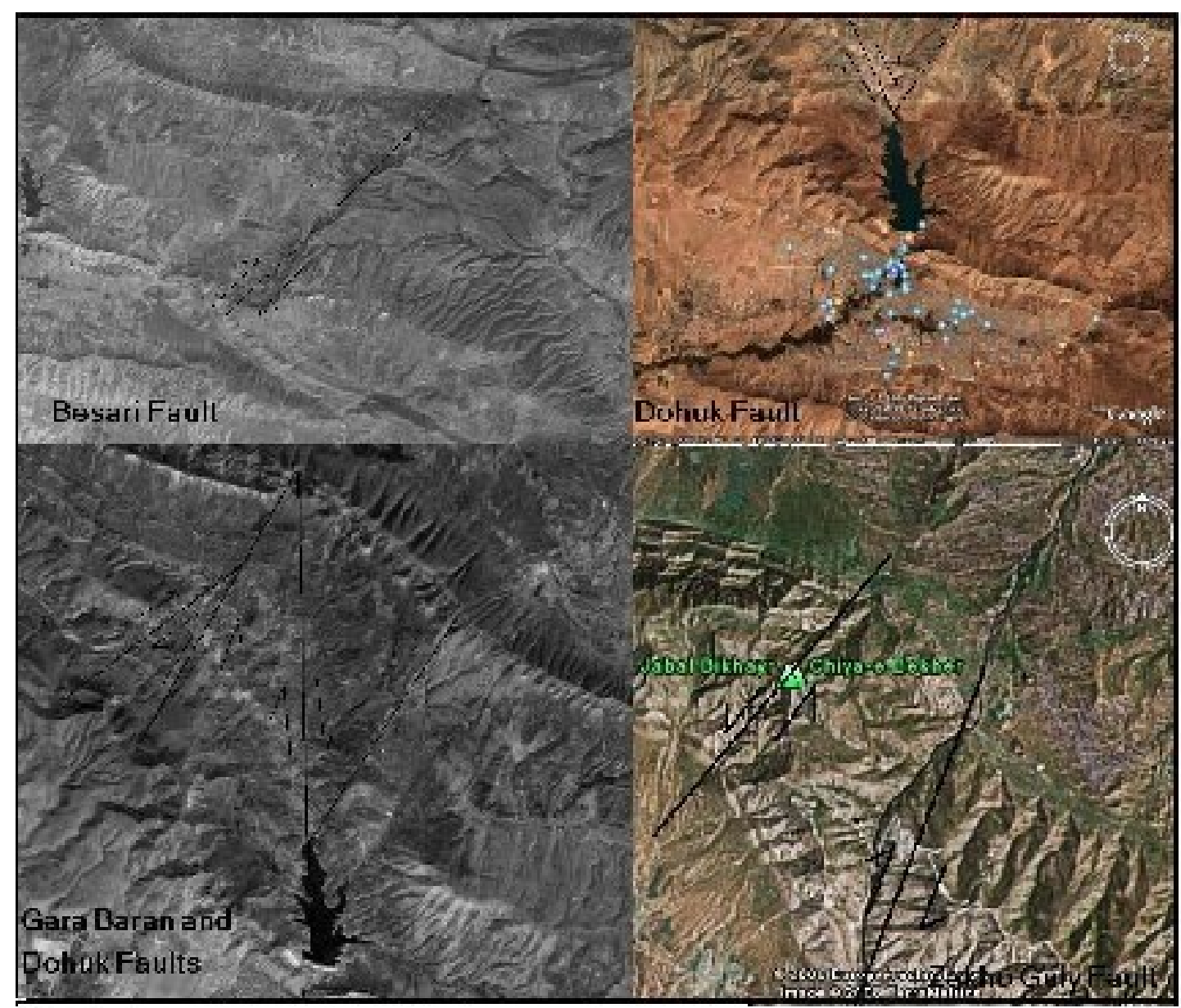

Fig. 8: Satellite images for the strike-slip faults.

\section{The vertical investigation of fold style:}

The data of the second and third traverses were considered for this investigation. This is because the oldest formations are exposed in the areas of these two traverses,. Other factors were used to investigate the intensity of folding through out the time span of the geological formations. These factors include the conformity of northeastern limbs, southwestern limbs, the fold axis and the values of interlimb angles. 
Figure (9a) shows Pi-diagrams for Shiranish, Kolosh, Gercus and Pila Spi formations of the first segment (the second traverse). These diagrams illustrate the attitudes of the northeastern limbs, southwestern limbs, the fold axes, the axial planes and the values of interlimb angles. The interpretation of these diagrams showed that there is very little difference between the folding of these formations. The northeastern limbs showed perfect coincident whereas the southwestern limbs fluctuated within $10^{\circ}$. These fluctuations may happened due to the effect of the foreland listric fault which had reactivated reversely toward the southwest in the first area. The intensity of folding which reflected by the values of interlimb angles indicates that folding was not gradual through the geologic time. It might be paroxysmal at the end of Tertiary succession deposition, and this is concordant with (Numan and Al-Azzawi, 2002; Jassim and Goff, 2006).

The Pi-diagrams of the third traverse (the second segment) revealed that the southwestern limbs for the fold in different geological formations are more or less coincident, whereas the northeastern limbs fluctuated within $10^{\circ}-11^{\circ}$ (Fig. 9b). This may be due to the effect of the suture listric fault which had reactivated reversely toward the northeast in this area. The analysis also revealed a distinct structural phenomenon, that is the vergence of the fold in the Shiranish and Kolosk formations towards the southwest whereas the fold in Gercus and Pila Spi formations verge northeasterly. This may indicates that the suture listric fault was reactivated during the deposition of Gercus formation (Middle Eocene).

\section{Baikher Anticline related faults:}

Sommaruga (1999) suggested that the Jura Foreland Folds were characterized by the interplay of foreland-vergent and suture-vergent faults that controlled the geometries of these folds. Numan and Al-Azzawi (1993) and Al-Azzawi (2003) emphasized the presence and nature of these listric faults in the Foreland Belt of Iraq. The most diagnostic properties of folds related to these listric faults are their asymmetry with a large difference in dips of the two limbs in the case of the foreland fault related fold, the forelimb became very steep and sometime vertical or overturned. And the fold verged toward the source of regional stress in the case of suture fault relating fold (Van der Pluijm and Marshak, 1997; Sommaruga, 1999; Al-Azzawi, 2003). On the other hand, the outline shape of Baikher Anticline influenced by several strike-slip faults (Fig. 2 and 8) which interpreted from satellite imagery. These faults, sometimes, changed the general trend of Baikher Anticline with sinistral and dextral strike-slip displacements.

According to that and results of the data analysis, the present study recognized two sets of faults in this area that influenced the geometry of Baikher Anticline. The first set is strike-slip faults that affected the outline shape and the fold trend. Whereas the second is a system of listric faults that influenced the cross-sectional shape and the fold vergence.

The strike-slip faults have affected the anticline in four distinct places (Fig.2). The first one is the southeastern plunge of Baikher Anticline. There is a dextral strike-slip fault(s) that influenced this plunge ST1. The southeastern block of this fault was uplifted and caused the broad shape and consequently made a bifurcated fold axis at this plunge. While its dextral strike-slip displacement continued southwesterly to influence the trend of Dohuk Anticline and made it swung towards the southeast. The second place is that 
where the dextral strike-slip displacements $\mathbf{S T 2}$ accommodated the movement of the foreland listric fault of the first segment with that of the suture listric fault of the second segment near Germawa valley (Fig. 8). The third place of such faults is near Kuwasha village where this anticlinal axis locally swung due to sinistral strike-slip displacement ST3. Lastly, the forth place shows very distinct strike-slip movements at Gali Zakho ST4, which made the anticline changed its direction by sinistral and dextral displacements from northwest-southeast to east- west direction.

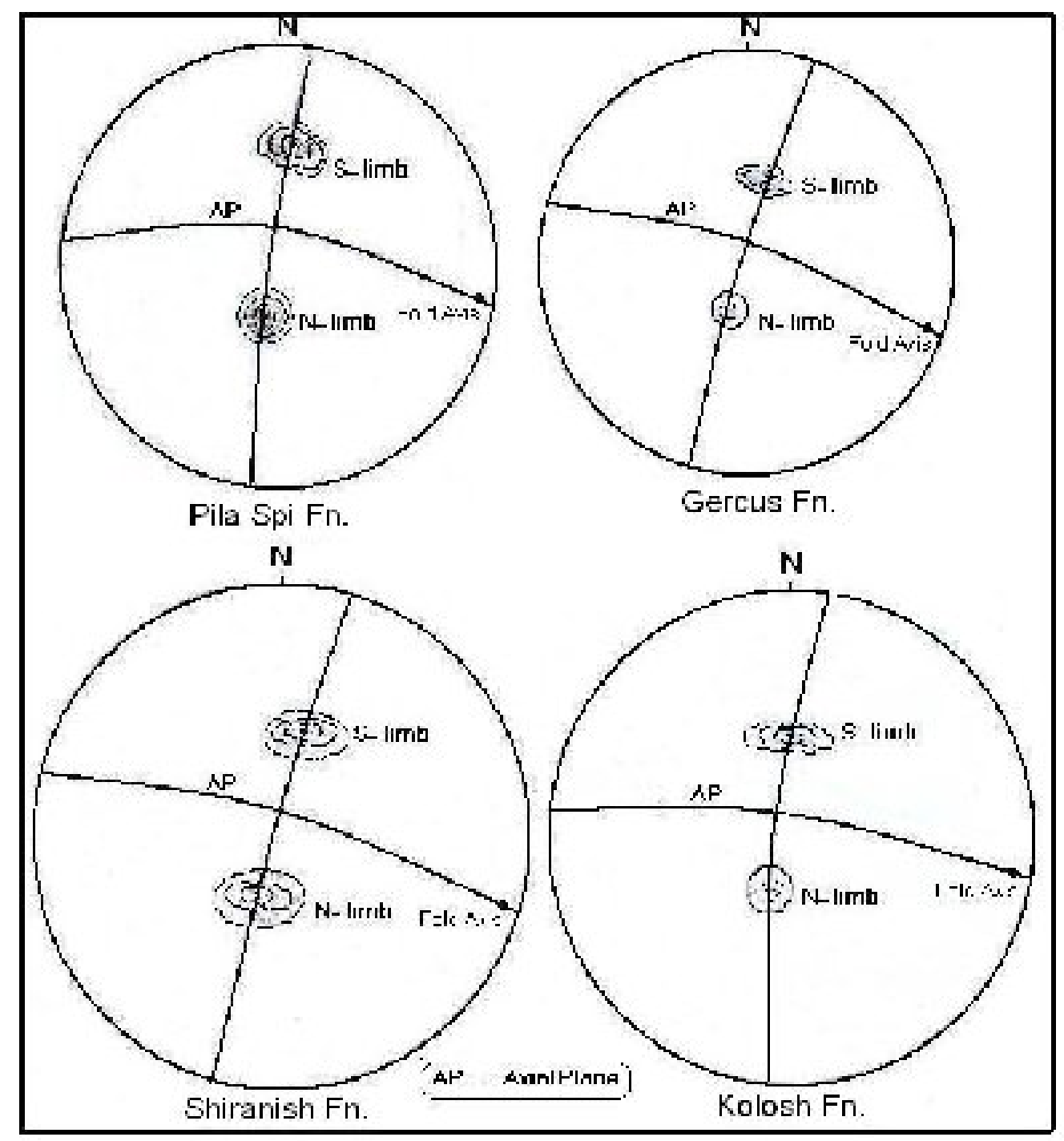

Fig. 9a: Pi-diagrams of the formation of the second traverse

It is also concluded that the opposing vergence of Baikher Anticline in three segments attributed to the interplaying of the listric faults that associated with the formation of Baikher Anticline. The first segment was influenced by the foreland listric fault, whereas the second one was affected by the movement of suture listric fault and the forth segment was interplayed also by suture listric fault with completely different fold axis orientation. The anticline showed that the effect of the suture listric fault in the second segment was died out at Kuwasha village, it means that the fold in the third segment affected only by the regional horizontal stresses. The presence of these listric faults were indicated by the fold opposing vergence and proved by the thickness changes 
of formations between the northern and southern limbs of Baikher anticline through out such segments (Table 2 and 3).

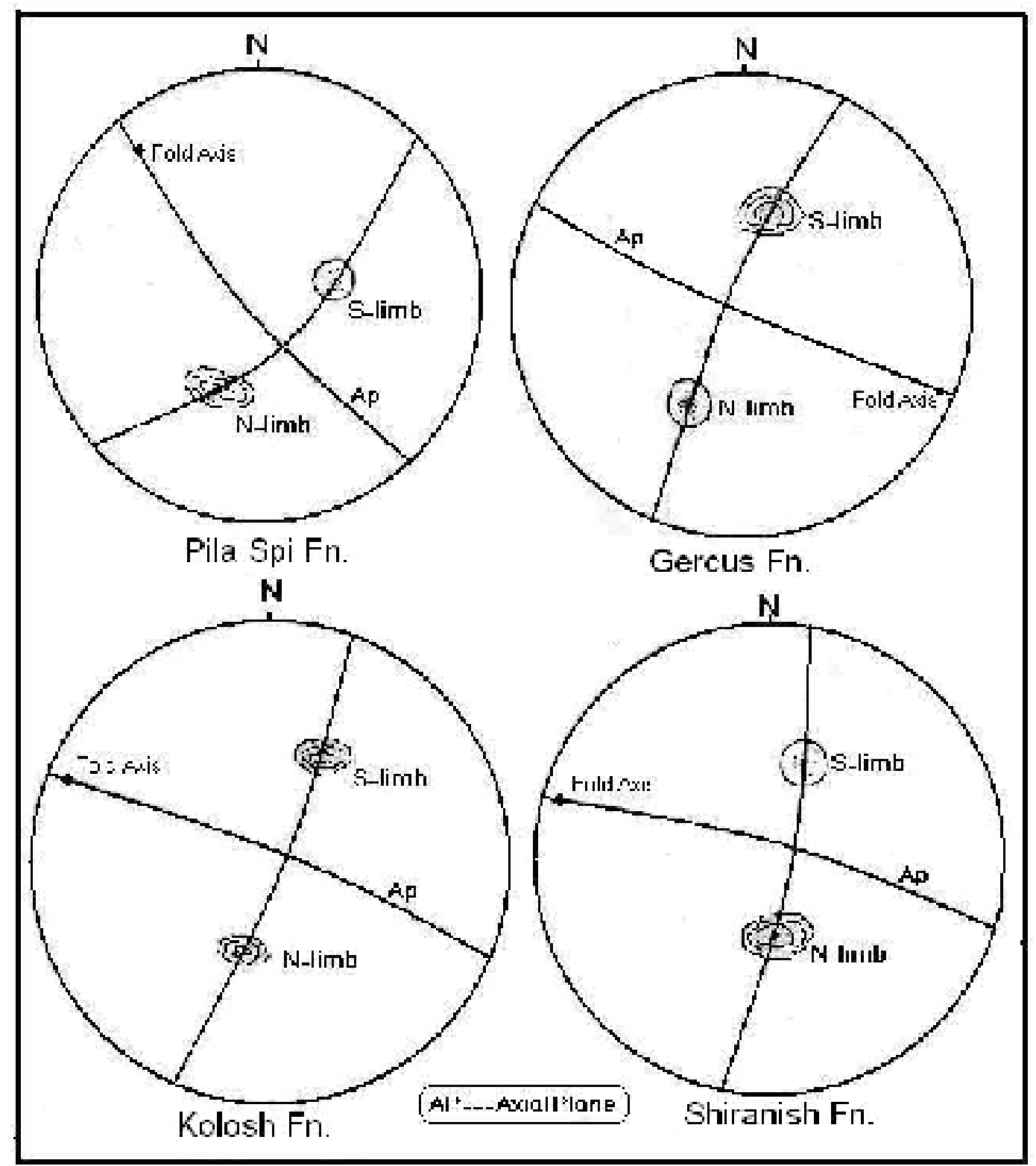

Fig. 9b: Pi-diagrams of the formation of the third traverse.

True thicknesses of the geologic formations were determined for studying the nature, types and displacements of these listric faults. Table (2) shows the true thicknesses of the geologic formations along the second traverse T2 (the first segment). The true thickness of each formation indicates the basin depth at the time of deposition. So that thicker formation reflects deeper basin and also indicate down-throw displacement. A vergence direction indicates dip of this listric fault, i.e. whether the fault is a foreland or hinterland (suture) verging type and a considerable difference of true thickness between the two limbs proves the interplay of the listric fault. 
Table 2. True thicknesses of formations in the second traverse T2.

\begin{tabular}{|l|c|c|}
\hline Formations & Southeastern limb $(m)$ & Northeastern limb $(m)$ \\
\hline Pila Spi Fn. & 636.3 & 436.5 \\
\hline Gercus Fn. & 626.2 & 652.2 \\
\hline Kolosh Fn. & 233.9 & 306.0 \\
\hline Shiranish Fn & 26 & 52.4 \\
\hline
\end{tabular}

The thickness values in table (2) point out that the basin of deposition was deeper in the area of the northeastern limb of the anticline from the Upper Cretaceous Epoch to the Middle Eocene Epoch (before the deposition of Pila Spi Formation). At the Middle Eocene Epoch, the basin inversion took place due to the inversion of listric fault displacement. And this is due to the continent- continent collision of the Arabian and Eurasian plates. This collision caused the pre-existing listric normal faults reactivated by reverse and normal sense of movements (Al-Azzawi, 2003). In the case of the first segment the pre-existing fault was reactivated as reverse fault which is called foreland listric fault (foreland-vergent fault). Consequently, this reverse movement influenced the vergence of the anticline in this part of Baikher Anticline. The relations between the true thicknesses and the basin depths are in concordance with the proposed movement of the foreland listric fault in the first segment.

The true thickness measurements of the geologic formations along the third traverse T3 (the second segment) are shown in Table (3). These measurements indicate that the basin of deposition was deeper in the area of the southwestern limb of the anticline during the deposition of the formations. This indicates that the pre-existing listric fault (of suture type) played as normal fault and caused Baikher Anticline in the second segment verged towards the northeast (the suture). This case was compatible with that similar structure of the Shaikhan Anticline (Al-Azzawi and Hamdoon, in press). The sense of movements of the foreland listric fault in the first area and the suture listric fault in the second area were accommodated by dextral strike-slip fault ST2 which was mentioned above.

Table 3. True thicknesses of formations in the third traverse T3.

\begin{tabular}{|c|c|c|}
\hline Formations & Southeastern limb $(m)$ & Northeastern limb $(m)$ \\
\hline Pila Spi Fn. & 944 & 928 \\
\hline Gercus Fn. & 481 & 469 \\
\hline Kolosh Fn. & 320 & 464 \\
\hline Shiranish Fn & 312 & 255 \\
\hline
\end{tabular}

The structure of the forth segment signifies the presence of another suture listric fault. Nevertheless, there is no reliable measurements of thicknesses and no formations exposed older than the Pila Spi Formation. The reverse interplay of this fault brought up the northern limb to sub-vertical attitude. 


\section{CONCLUSION}

The field observations, satellite image analysis and analysis of the field collected data exposed many points that may be considered as conclusions or new contributions to the field of knowledge of this area.

1- Baikher Anticline is a double plunging anticline. Its southeastern plunge is very broad and characterized by bifurcating axis.

2- It is asymmetrical anticline with varied vergence, open to gentle, cylindrical fold in all studied traverses.

3- It is reasonable to divide Baikher Anticline was according to axial trend and fold vergency into four segments. The first one extended from Zawita/Besari to Germawa Valley. Whereas the second segment started from this valley to Kuwasha village, the third one extended to Gali Zakho and the forth segment occupied the area between Gali Zakho and the western plunge.

4- The tectonic style changes of the fold depended on three factors. That is the fold cylindricity, the interlimb angle and the fold shape in cross-section. The first two factors showed no variations through out the studied traverses. But the analysis revealed considerable differences in fold shape which signified the division of the fold into four segments (i.e. each segment has diagnostic shape of the limbs).

5- Baikher Anticline was dissected by two sets of faults. The first is a set of strike-slip faults which influenced the outline shape of the anticline. These are the dextral fault at the southeastern plunge $\boldsymbol{S T 1}$, the dextral one at Germawa valley $\boldsymbol{S T 2}$, the sinistral fault of Kuwasha local swing ST3 and the sinistral and dextral fault at Gali Zakho ST4. The another set is the listric faults that affected the vergence of Baikher Anticline in the four areas. These are The foreland listric fault that caused the anticline verging towards the southwest in the first segment, the suture one which caused the anticline to verge northeastwards in the second segment and also the suture fault in the forth segment which caused the fold in this area to acquire a vergence towards the north.

6- The pre-existing faults appeared to be reactivated at M. Eocene Epoch while the paroxysmal folding happened at the Pliocene Period. This indicates that the faulting proceeded the folding during the course of the foreland belt deformation.

7- Lastly, it is suggested here to rename the Foreland Folds Belts of Iraq as the Foreland Folds/Faults Belt. This is because the association of different types of faults with the formation of the fold in this belt, i.e. most of them are fault related folds (comparing with the previous study).

\section{REFERENCES}

Al-Alawi, M.N.T., 1980. Structural Geology of Bekhair Anticline - Northern Iraq, Unpublished. M. Sc. Thesis, University of Mosul, Iraq.

Al-Azzawi, N.K.B., 2003. The Structural Development of Fold Shape in the Foreland Belt of Iraq and Its Tectonic Implications, Unpublished Ph.D Thesis, College of Science, University of Mosul, Iraq, 208p.

Al-Azzawi N.K.B. and Hamdoon A.N., 2008. Structure and Geomorphology of Shaikhan Anticline Northern Iraq, Iraqi Jour. of Earth Science, Vol. 8, No. 1, pp. 54-63. 
Al-Duski, J.A.H., 2004. A New Contribution to the Structural Geology of Dohuk Area (Kurdistan-Iraq), Dohuk University., Vol. 7, No. 2, 6 p.

Al-Shaibani, H., 1973., The Geology of Chia Spi (Spi Rais and Geri Baran Domes), INOC Library, Baghdad.

Ameen, M.S., 1979. Regional Investigation of Geoflexures and Tectonic Analysis in the Simple Folded Zone of Iraq, Unpublished M.Sc. Thesis, University. of Mosul, Iraq.

Bolton, C.M.G., 1958. The Geology of Rania Area, Site Invest. Co. Rep. Vol. IXB 117p, D.G. Geol. Surv. Min. Inves. Lib. Rep. No. 271 Baghdad, Iraq.

Fleuty, M.J., 1964. The Description of Folds, Geol., Ass., Proc., Vol. 75, Pt. 4, pp. 461-492.

Hobbs, B.E., Means, W.D. and Williams, P.F., 1976. An Outline of Structural Geology, John Wiley and Sons. Inc., New York, 571P.

Hudleston, P.J., 1973a. Fold Morphology and Some Geometrical Implications of Theories of Fold Development, Tectonophusics, 16, pp.1-46.

Jassim S.Z. and J.C. Goff, 2006. Geology of Iraq, Dolin, Prague and Moravian Museum, Brno, Czech Republic, 341p.

Numan, N.M.S., and Al-Azzawi, N.K.B., 1993. Structural and Geotectonic Interpretation of Vergence Directions of the Anticlines in the Foreland Folds of Iraq, Abhath Al-Yarmouk (Pure Science and Engineering), Yarmok University, Jordan, Vol. 2, No. 2, pp. 57-73.

Numan, N.M.S., and Al-Azzawi, N.K.B., 2002. Progressive Versus Paroxysmal Alpine Folding in Sinjar Anticline Northern Iraq, Iraqi Jour. of Earth Sciences, Vol. 2, No. 2, pp. 59-69

Ramsay, J.G., and Huber, M.I., 1987. The Techniques of Modern Structural Geology: V.2, Folds and Fractures, Academic Press, London, UK, 700p.

Rickard J.L., 1971. Introduction to Geological Maps and Structures, NewYork, 332p.

Singh, R.A., and Gairola, V.K., 1992. Fold Shape in the Vicinity of North Almora Thrust in District Chamoli, Garhwal Himalaya, Journal of Himalayan Geology, Vol. 3, No.2, pp. 121-129.

Sommaruga, A., 1999. Decollement tectonics in the Jura Foreland Fold-and- Thrust Belt, Marine and Petroleum Geology, Vol. 16, pp. 111-134.

Stabler, C.L., 1968. Simplified Fourier analysis of Fold Shape, Tectonophysics, Vol. 6, No. 4, pp. 343-350.

Taufiq J.M., and Domas, J., 1977. Report on the Regional Geological Mapping of Duhok - Ain Zalah Area. Unpublished SOM report, No. 837, SOM library, Baghdad.

Turner, F.J. and Wiess, L.E., 1963. Structural Analysis of Metamorphic Tectonite, NewYork, 525p.

Van Bellen, R.C., Dunnington, H.V., Wetzel, R. and Morton, D.M., 1959, Lexique Stratigraphique International, National de la recherché scientifique, 13, quai, Anatole-France, Paris- VII, 333p.

Van der Pluijm, B.A., and Marshak, S., 1997. Earth Structure: An Introduction to Structural Geology and Tectonics, WCB/McGraw-Hill, USA, 495p. 